\title{
COMPORTAMENTO DO PESSOAL DE ENFERMAGEM NA ADMISSÃO DA CRIANÇA AO HOSPITAL*
}

\author{
Lélia Maria Madeira**
}

MADEIRA, L. M. Comportamento do pessoal de enfermagem na admissáo da criança ao hospital. Rev. Esc. Enf. USP, São Paulo, 18(3):235-253,1984.

No trabalho analisa-se, qualitativamente, o processo de admissáo da criança, feito pelo pessoal de enfermagem, em um hospital geral governamental e destaca-se o papel do(a) enfermeiro(a). Isto é feito com a finalidade de se obterem subisios para a compreensão do envolvimento do profissional neste processo e para auxilio ao encaminhamento de uma pesquisa participante, a ser feita posteriormente, com a equipe de enfermagem da unidade pediatrica.

\section{INTRODUÇÃO}

A admissão da criança ao hospital sempre foi vista pela autora como uma situação crítica e delicada para a criança e família. Como enfermeira de unidade e como docente de enfermagem pediátrica, foi possivel sentir todas as deficiências desse processo. $\mathrm{O}$ que sempre nos chamou a atenção, e que consideramos muito sério, é que, em toda bibliografia consultada, os autores são unânimes em suas recomendações; recomendam uma admissão bastante completa do ponto de vista da enfermagem; sempre se referem a uma assistência à criança, global e sistematizada considerando os aspectos bio-psico-sócio-espirituais; enfatizam a necessidade de boa assistência aos pais; enfim, preconizam que a assistência à criança e família, na admissão, deve favorecer a adaptação ao hospital, bem como o tratamento da criança e o retorno ao lar o mais rápido possível, e com o mínimo de seqüelas provocadas pela hospițalização.

O que se percebe na prática de enfermagem, mesmo empiricamente, é

* Trabalho apresentado à Comissão de Pós-Grad uação da Escola de Enfermagem da USP para Exames Gerais de Qualificaçăo do Curso de Pós-Graduação - nível mestrado.

* Mestranda em Enfermagem da Escola de Enfermagem da USP. Professor Assistente da disciplina Enfermagem Pediátrica da Escola de Enfermagem da Universidade Federal de Minas Gerais. 
que o processo de admissão da criança deixa muito a desejar, considerando o que, cientificamente, se recomenda, pois a criança não é assistida integralmente; tenta-se atender as suas necessidades físicas, mas outras, de importância igual ou maior, ficam relegadas.

O estudo exploratório "Problemas de internação em pediatria", feito anteriormente pela pesquisadora, ampliou mais a visão do problema e aumentou as preocupações já existentes em relação à situação.

Assim, neste trabalho, optamos por estudar a admissão da criança em unidade pediátrica de um hospital-escola governamental. A escolha desta instituição deveu-se ao fato da autora já ter trabalhado ali 3 anos. Esta vivência proporcionou-lhe, além da estima e respeito pelo pessoal de enfermagem, o conhecimento da problemática da admissão da criança, das deficiências da assistência, bem como das dificuldades enfrentadas por ele.

A unidade pediátrica tem capacidade para 52 leitos, com duas alas: ala A (22 leitos) e ala B (30 leitos). A equipe de enfermagem que presta serviços nas 24 horas é composta por 9 enfermeiras, 39 auxiliares de enfermagem e 10 atendentes.

Em relação à admissão da criança propriamente dita, feita pela enfermagem, o procedimento de rotina na unidade é o seguinte:

- a enfermeira é comunicada sobre a internação da criança, pelo residente de plantão;

- ela determina onde a criança vai ficar e comunica à auxiliar responsável;

- após triagem feita no Posto Médico de Internação (PMI), a criança chega à unidade, acompanhada dos pais ou responsável e por um funcionário do PMI;

- a criança é examinada pelo médico residente que faz a anamnese e o exame físico;

- a criança é encaminhada à enfermeira junto com a mãe e entregue aos cuidados da auxiliar de enfermagem;

- a auxiliar verifica sinais vitais e peso e providencia o banho da criança;

- a criança é colocada no leito;

- a mãe é encaminhada para a assistente social que preenche a ficha social;

- a enfermeira faz o registro da admissão no livro, verifica e transcreve a prescrição médica, elabora o plano de cuidados de enfermagem que consta do prontuário, encaminha e providencia exames e tratamentos. 
A admissão feita no dia-a-dia é a descrita, podendo ocorrer variações, uma vez que são comuns as internações de urgência, quando se faz necessário atuar rápidamente na implementação da terapêutica. Nestes casos, há o trabalho conjunto médico-enfermeira-auxiliar de enfermagem e outros; geralmente a enfermeira presta cuidados diretos à criança, orienta a auxiliar de enfermagem e toma as providências que são de sua competência.

Em face da problemática mencionada, surgiu a idéia do presente trabalho, visando, especialmente, a análise qualitativa da admissão da criança, feita pelo pessoal de enfermagem nesta unidade.

Como $\mathrm{BOSI}^{3}$, em seu trabalho, faz-se necessário ressaltar que os dados a serem utilizados servirão apenas como expediente didático, para ilustrar a problemática analisada, sem nenhum comprometimento de ordem estatística.

Com este trabalho pretendemos obter subsídios que auxiliem a compreensão da pesquisadora e também da equipe de enfermagem sobre a atuação do(a) enfermeiro(a) neste processo. Esta compreensão, provavelmente muito ajudará no encaminhamento da pesquisa que está sendo implementada junto à equipe, onde é utilizada a metodologia de pesquisa participante e cujo tema é a "Hospitalização da Criança".

Sabendo que a admissão representa momento muito importante na hospitalização da criança, acreditamos que este trabalho poderá ser muito útil no desenrolar das discussões propostas com o grupo citado.

Para isto, procuraremos atender aos seguintes objetivos:

- análise crítica do processo de admissão da criança, feito pela enfermagem, nesta unidade específica;

- caracterização do papel do(a) enfermeiro(a) neste processo.

Efeitos da hospitalização sobre a criança e a família

A hospitalização de crianças é uma ocorrência rotineira em nossa prática hospitalar, sendo conhecidos os altos índices de admissão de crianças que chegam às nossas instituições pelos mais variados problemas.

Considerando nossa realidade de pais em desenvolvimento, sabemos das condiçб̄es de atendimento que são oferecidas pelas instituiçðes à população infantil. Como bem coloca BARBOSA ${ }^{2}$, o excesso de doentes e a escassez de recursos traz dificuldades em se estabelecerem prioridades, e a tendência geral é relegar aspectos básicos da assistência à criança, em favor de outros que estão mais afetados.

A hospitalização traz consigo muitos malefícios para a criança e sua fa- 
mília. Para a criança, segundo MARCONDES ${ }^{10}$, a hospitalização é quase sempre um duplo traumatismo, pois ela tem que se separar do ambiente familiar e entrar num ambiente hostil que é o hospital. A maioria dos autores, entretanto, é unânime em considerar que a separação da mãe é a que provoca mais efeitos nocivos à criança quando é hospitalizada.

Este fenômeno, apesar de não ocorrer apenas em instituições hospitalares, é uma constante em nosso meio; conforme bem colocam ROBERT$\mathrm{SON}^{16}$, SPITZ ${ }^{19}$ e BOWLBY ${ }^{4}$, pode ter conseqüencias desde aquelas recuperáveis, até as indeléveis para a vida da criança.

Para BOWLBY ${ }^{4}$, são verificadas diversas formas de desajustamento da personalidade - histeria, incapacidade de afeição, delinqüência - como também vários estados de angústia e depressão que foram originados ou exacerbados por experiências de privação materna. $O$ autor destaca, ainda, a necessidade da continuidade do relacionamento mãe-filho para o desenvolvimento da criança e da mãe.

HERTL $^{7}$ enfatiza a relação estreita existente entre mãe e filho e afirma que, na situação de hospitalização do filho, a mãe o acompanha não só como informante de sua doença, mas também como participante dela, podendo mesmo ser considerada doente também.

Para BARBOSA ${ }^{2}$, são muitos os fatores que vão influenciar os efeitos da hospitalização sobre a criança: idade, situação psico-afetiva, relacionamento prévio com a mãe, personalidade e capacidade de adaptação da criança, experiências satisfatórias ou não vividas durante a hospitalização, duração da hospitalização, rotinas hospitalares e atitude da equipe hospitalar.

Em relação à atitude da equipe hospitalar, acredita-se que muito se pode fazer pela criança e sua família, para que a experiência da hospitalização seja atenuada e favoreça o desenvolvimento tanto da criança quanto da família.

Para isto, ao discorrerem sobre a admissão da criança, os autores recomendam a atuação efetiva do(a) enfermeiro(a) neste processo, dentro de princípios científicos, vendo a criança dentro de seu contexto sócio-econômico-cultural.

Por outro lado, existe uma gama de problemas que compõem o quadro da assistência à criança, particularmente os ligados à enfermagem, tais como: despreparo técnico-científico do pessoal, sobrecarga de trabalho, assistência voltada quase que só para aspectos físicos, não permissão da mãe acompanhante, entre outros.

- O que fazer para modificar tal situação?

NOWINSKI \& RIPA $^{13}$, ao tratarem da problemática da investigação nos 
hospitais, salientam que o hospital deve contribuir para o conhecimento mais profundo da realidade; mas que não é suficiente tomar consciênciàdos problemas existentes se não aprendemos a abordá-los, baseados em uma metodologia científica.

No que se refere à enfermagem, esta colocação parece bastante pertinente. De modo geral, sabemos da precariedade da assistência prestada a nossos clientes, porém, o difícil é encontrar a maneira adequada de abordar a questão e sugerir alguma solução.

Autores como MACHADO \& $\mathrm{MACHADO}^{8}, \mathrm{ROCHA}^{17}$ e CONCEIÇÃO et alii $^{5}$ sentem, como essencial para o equacionamento dos problemas de saúde da criança, a necessidade da existência de filosofia de trabalho, embasada numa visão global de saúde da criança. Os autores afirmam que esta assistência torna-se inexeqüível se divorciada do sentido de trabalho em equipe.

- E como se posiciona o profissional enfermeiro(a) nesta situação?

Em pesquisa realizada por FERREIRA-SANTOS ${ }^{6}$, onde é feito um perfil psicológico, social e cultural do enfermeiro, foi verificado que o papel do(a) enfermeiro(a) está mal integrado no sistema hospitalar e na sociedade em geral, e que a profissão se encontra em processo de transição no que se refere à definição de papéis. A autora diz, também, que os conhecimentos teóricos dos anos de formação do enfermeiro não têm sido acompanhados de modificaçōes na esfera do agir.

Uma forma de atingir mudanças desejadas na profissão é proposta por MINZONI ${ }^{12}$, através da função integrativa.

Esta função exige do enfermeiro conhecimentos mais amplos, não só de enfermagem, mas também de outras ciências como a psicologia e sociologia. Para a autora, a função integrativa "é um modo de agir com o outro (pessoa, família ou grupo), como ser humano capaz̄ de pensar e tomar decisões"; e que, ao executá-la, o enfermeiro retornaria ao cuidado direto às pessoas que requerem ajuda, atuaria nos diversos níveis de prevenção e atenderia à necessidade urgente de renovação do ensino, para que suas açбes sejam condizentes com a evolução da enfermagem.

- Estarão as(os) enfermeiras(os) preparadas(os) para desempenhar tal função?

- Estarão, pelo menos, conscientes da profundidade e importância de seu papel junto ao cliente?

Tentando responder a estas e outras indagações, passaremos a analisar o processo de admissão da criança, feito pelo pessoal de enfermagem, naquela unidade pediátrica, citada anteriormente. 
Numa visita feita à unidade de internação, durante 3 dias, após contactar com a equipe de enfermagem e explicar o motivo de nossa presença ali, foram feitas observações assistemáticas de duas admissões e, também, uma entrevista com pergunta aberta às enfermeiras e auxiliares de enfermagem envolvidas nestas admissões.

Os objetivos, nesse momento, eram: caracterizar o processo de admissão da criança nesta unidade e conhecer a percepção do pessoal de enfermagem sobre o mesmo.

\section{Primeira observação}

Através dos dados desta observação (Anexo 1) podemos ressaltar que, quanto à atuação da enfermeira $\mathrm{A}$, verificamos algumas açס̄es esperadas do profissional e consideradas positivas, enquanto outros pontos que ficaram omissos.

Como positivo foram observados o relacionamento e a comunicação com os pais da criança: preocupa-se com eles, procura conhecer e solucionar suas dificuldades (banho para a mãe, alimentação, abrigo), mostra as dependências da unidade, informa sobre horário de visitas, permite que a mãe preste os primeiros cuidados à criança.

Ainda, como positivo, vimos que o comportamento da enfermeira $\mathrm{A}$ foi independente ao admitir a criança antes do exame médico, levando em consideração a situação da família e deixando de lado as normas e rotinas da unidade.

Sabemos o quanto é raro, na prática de enfermagem, especialmente hospitalar, que o profissional se liberte das rotinas institucionalizadas, tomando atitudes coerentes com seu preparo técnico-cientrfico e orientadas para as reais necessidades do paciente. $O$ que é verificado, com freqüência, é uma acomodação dentro daquelas normas e rotinas, mesmo quando já desgastadas, sem que haja apreciação bem fundamentada da aplicação das mesmas.

Outros procedimentos recomendados pelos autores, e considerados básicos na admissão da criança, não mereceram a atenção da enfermeira $\mathrm{A}$, por exemplo, no contato com a criança; este era o caso de uma criança escolar, que já compreende as explicações dadas e pode fornecer informaçōes sobre si, desde que seja usada abordagem correta e que ela perceba que existe interesse verdadeiro por sua pessoa. No entanto, a enfermeira A, durante o período de observação, não abordou a criança em nenhum momento. Apesar de ter interagido com os pais, na admissão, não colheu informação alguma que pudesse ampliar seu conhecimento sobre a criança e a família, para orientar melhor sua conduta. 
Autores como PETRILLO \& SANGER ${ }^{14}$ enfatizam a importância da entrevista com a criança e família, no momento da hospitalização. Falam do valor da entrevista para toda a equipe hospitalar e afirmam que esta entrevista serve como guia inicial para todas as pessoas que interagem com a criança e sua família na unidade pediátrica, durante os primeiros dias de sua internação.

Outra ação básica, que norteia a assistência de enfermagem à criança recém-chegada, é a elaboração da prescrição de enfermagem, ou seja, do plano de cuidados de enfermagem. Através da prescrição o(a) enfermeiro(a) fornece subsídios, principalmente a seu pessoal, para a orientação da assistência que deverá ser prestada ao paciente, baseando-se em suas necessidades básicas, reais; para isto, é imprescindível que o(a) enfermeiro(a) avalie as condiçōes gerais do cliente, através de observaçðes, de dados colhidos e, principalmente, através do exame físico.

Para ALEXANDER \& BROWN ${ }^{1}$ o exame físico da criança é uma atividade da enfermeira e, ao desempenhá-lo, o profissional precisa ser rigoroso e metódico, sabendo, porêm, adaptar o método à situação e à idade da criança.

No caso observado isto não aconteceu e também o plano de cuidados sô foi elaborado mais tarde pela enfermeira do plantão noturno. Nesta unidade as enfermeiras elaboram o plano de cuidados de todas as crianças mas, para isto, na maioria das vezes, esperam ter em mãos a prescrição médica. Assim, o fato de enfermeira A não ter feito o plano da criança sugere ser o motivo a inexistência da prescriçąo médica até o momento observado.

Mesmo o plano elaborado mais tarde, após prescrição médica, como pode ser o visto no Anexo 2, atende apenas a algumas necessidades físicas da criança, deixando muito a desejar, se considerarmos as necessidades bio-psico-sôcio-espirituais desta criança, que é um escolar, de outro estado, que se estava separando dos pais e com suspeita de estar com câncer.

Quanto à atuação da auxiliar de enfermagem $a$, percebe-se um relacionamento mais efetivo com a criança, procurando facilitar sua adaptação ao hospital e atendendo às suas necessidades físicas e emocionais.

\section{Segunda observação}

Aqui verifica-se, como se vê no Anexo 3 que tanto a enfermeira $B$ quanto a auxiliar de enfermagem $b$ atenderam a criança comportando-se de forma indiferente, tomando atitudes bastante automatizadas e com a atenção voltada apenas para procedimentos técnicos e aspectos físicos da assistência.

Para $\mathrm{RIBEIRO}^{15}$, as pessoas responsáveis pela assistência à criança hos- 
pitalizada parecem não ter, ainda, idéia clara dos problemas causados à criança pela separação dos pais e hospitalização.

$\mathrm{Na}$ admissão observada, o relacionamento do pessoal de enfermagem com a criança e a acompanhante foi impessoal e indiferente; não se verificou preocupação em atender às necessidades emocionais da criança, que demonstra alto nível de "pavor" na situação que vivenciava.

Considerando a importância do relacionamento efetivo enfermagem-criança-família durante a admissão, poderíamos dizer que, no caso, não houve relacionamento.

ROSKIES et alii ${ }^{18}$ mostram a diferença de comportamento das enfermeiras em uma admissão de emergência, comparada com uma admissão programada da criança; dizem que, no caso de uma admissão de emergência, como consideramos o caso de nossa análise, a enfermeira tem maior dificuldade em lidar com a situação por estar em grande conflito, em virtude de ter que responder a duas expectativas de sua função, que seriam: agir tecnicamente, conforme a situação exige, através de procedimentos estritamente regulados e definidos, e, ao mesmo tempo, considerar as necessidades psicológicas da criança. Como é de se esperar, é o aspecto afetivo de seu papel que, freqüentemente, é abandonado.

MENZIES ${ }^{11}$ explica esta despersonalização e distanciamento da enfermeira em relação a seu paciente, como uma forma de fugir de sua própria ansiedade, através de um mecanismo de defesa institucionalizado pelo pessoal de enfermagem; este mecanismo tem como objetivo o controle da ansiedade provocada na enfermeira pela própria situação de "stress" que vivencia.

Quanto às açðes específicas da enfermeira $\mathrm{B}$, verificamos que muitos aspectos não foram abordados nesta admissão: não houve entrevista com o acompanhante, não foi feito exame físico da criança; e mais, o plano de cuidados elaborado não atendia sequer às necessidades físicas da criança (Anexo 4).

Pelo visto, é imperativo que o(a) enfermeiro(a) se conscientize da importância da admissão para a criança e família e que direcione suas açôes para uma assistência indivídual, globalizada, considerando não só os aspectos físicos da criança, como também os psico-sócio-culturais.

Acreditamos que só um profissional bem preparado poderá compreender e atender a toda gama de necessidade da criança e família, atuando para sua completa recuperação após uma experiência tão desagradável como a hospitalização. 


\section{Entrevistas}

Utilizando a pergunta "O que você pensa da admissão da criança? ", foi realizada uma entrevista com enfermeiras e auxiliares de enfermagem envolvidas no estudo, cujas respostas são relatadas a seguir:

Enfermeira $A$ - Acha a admissão traumatizante mais para a criança do que para a família; vê como a quebra do relacionamento mãe-filho, numa situação de doença.

A criança vai mudar toda sua rotina de vida, num ambiente estranho. A enfermeira preocupou-se em mostrar o banheiro, copa e demais dependências para a criança maior. Há crianças que não se adaptam ao hospital e a mãe precisa ficar com elas.

Acham que precisa conversar mais com a mãe, obter mais informaçðes sobre a criança e seus hábitos; sabe como isto e importante, e fazia assim em outro hospital.

Acha que os planos de cuidados de enfermagem são "vergonhosos", baseados apenas em prescriçôes médicas. Precisam melhorar cientificamente.

Enfermeira $B$ - Preocupa-se em saber a doença, o diagnóstico, em conhecer a criança (temperatura, peso), para estabelecer sua conduta.

Quanto ao emocional, acha difícil fazer alguma coisa. $\mathrm{Na}$ admissão, suas preocupações são outras e mais prioritárias, tais como: arranjar o leito, providenciar isto, aquilo. Conversa com a família, gosta de informar sobre visitas e normas do hospital.

Percebem-se pontos de vista diferentes em relação à admissão da criança.

Pelas colocações da enfermeira A, percebe-se uma visão mais científica do procedimento: ela se refere aos efeitos nocivos da hospitalização sobre a criança e os pais; reconhece deficiências da assistência e indica condutas a serem tomadas para melhorar estas deficiências.

Por outro lado, se retomarmos a descrição da primeira admissão (Anexo 1), poderemos verificar algumas incongruências entre o que é verbalizado e o que é feito, realmente. Por exemplo, valoriza a entrevista com a mãe "para obter mais informaçðes sobre a criança" e, no entanto, isto não foi feito; falou da importância do plano de cuidados, mostrando até insatisfação com o que está sendo feito, porém, o da sua paciente não foi elaborado por ela.

Já a enfermeira B mostra conhecimento mais limitado sobre a admissão; não percebe a criança como um todo; preocupa-se com aspectos de procedimentos de enfermagem, em executar atividades técnicas no momento 
da admissão e em saber o diagnóstico da criança, para estabelecer sua conduta.

Comparando o que diz e o que faz no processo de admissão, podemos perceber que ela parece estar um tanto "atrapalhada" com a parte emocional da criança. Não demonstra saber o que fazer para resolver este aspecto da assistência; parece apegar-se àqueles que consegue resolver, que são os relacionados aos procedimentos técnicos.

Auxiliar de enfermagem $a$ - Acha que o melhor é receber bem a criança, dar apoio, conversar com ela, mostrar que pode sentir-se em casa. Às vezes, vê crianças tristes e deprimidas e acha que não é pela doença, é porque não estão se sentindo apoiadas. Quanto às mães acha que precisam de apoio, de serem bem tratadas, para poderem aprender a dar mais carinho para o filho.

Auxiliar de enfermagem $b$ - Acha que a admissão é feita de forma mecânica, não sabe porque isto ocorre. Talvez porque sejam feitas tantas, todos os dias.

Diz que, quando se conversa com a criança na admissão, ela aceita melhor o hospital. Quando se conversa com a mãe, ela cria coragem para se aproximar e perguntar as coisas. Se a auxiliar faz tudo calada, sem explicar o que está fazendo, causa medo e inibição na mãe.

Acha que esta forma mecânica de admitir a criança precisa melhorar.

Nestas respostas encontramos níveis diferentes de percepção quanto ao significado da admissão para ambas.

A auxiliar de enfermagem $a$ mostra grande preocupação em atender às necessidades da criança e da mãe e em ajudar a criança em sua adaptação ao hospital. Realmente, foi o que procurou fazer quando admitiu a criança. Ela vê o tratamento humanizado como a base para a assistência à criança $e$ à mãe.

No 20 caso, a auxiliar de enfermagem $b$ é capaz de identificar a dificuldade que percebe, não sabe bem o motivo, mas acha que precisa melhorar. Considera importante a parte de comunicação auxiliar-criança-mae; preocupa-se com a adaptação da criança e da mãe no hospital.

Novamente, nos deparamos com uma grande contradição entre o que se diz e o que se faz. Voltando à descrição da 2ạ admissão (Anexo 3), vê-se que nada do que ela valoriza foi colocado em prática.

Aqui caberiam algumas perguntas:

- o que levaria o pessoal de enfermagem a não atuar dentro de seus princípios profissionais, baseados em seus conhecimentos técnico-científicos? 
- que influência estaria tendo o(a) enfermeiro(a) sobre a atuação do(a) auxiliar de enfermagem?

- o que levaria os(as) enfermeiros(as), de modo geral, a manterem determinados padroes de comportamento, apesar de saberem que estes não são os mais apropriados?

MENZIES ${ }^{11}$ refere-se a resistềncia à mudança, presente no pessoal de enfermagem, como um dos mecanismos de defesa utilizados contra a ansiedade, e explica que qualquer mudança significativa dentro do sistema social implica em mudanças nas relações sociais existentes e na estrutura. Diz ser compreensível que o serviço de enfermagem, cujo trabalho estimula ansiedades primitivas e intensas, resiste à mudança como forma de evitar uma ansiedade excepcionalmente severa. Para isso, tenta fugir da mudança, na medida do possível, quase a qualquer preço. Tende a agarrar-se àquilo que é conhecido, mesmo quando este cessou de ser o mais apropriado e importante.

Além disso, poderíamos mencionar outras causas que, provavelmente, estariam contribuindo para a manutenção de tal situação. É conhecida a quase inexistência de educação continuada nos hospitais, o que leva à acomodação dos profissionais; nestas instituiçðes não se encontra, de modo geral, pessoa alguma que demonstre interesse real em facilitar e promover o crescimento dos(as) enfermeiros(as). Na maioria das vêzes, o que se requer, para o bom desempenho de suas atividades, nada mais é do que a simples acomodação às rotinas da clínica, sem deles exigir qualquer criatividade, o que está aquém de sua capacidade como profissionais.

Quanto à admissão da criança, não estariam todos estes fatores influenciando o desempenho do pessoal de enfermagem (enfermeiras e auxiliares de enfermagem) e levando a situação ao ponto em que se encontra?

\section{CONCLUSÕES}

Pelo exposto, apesar das limitaçðes das observaçð̃es e das entrevistas, partindo, principalmente, do conhecimento prévio da situação e da análise qualitativa da problemática, tentamos esboçar algumas conclusões sobre a admissão da criança, bem como do papel que o enfermeiro desempenha neste processo.

Na situação analisada, podemos dizer que a admissão da criança ocorreu de forma incompleta e deficiente: o relacionamento enfermagem-criança-família foi mínimo neste momento; a enfermeira não esteve atenta para informaçðes sobre a criança, que poderiam auxiliá-la no planejamento da assistência; o plano de cuidados de enfermagem foi falho.

Quanto ao desempenho do papel do(a) enfermeiro(a), propriamente dito, 
não percebemos atuação efetiva. A admissão para elas representou mais um procedimento administrativo do que, realmente, um procedimento de enfermagem. Sua atuação não foi sistematizada; foi pouco fundamentada cientificamente, e muito orientada pela rotina existente na clínica.

Pelo exposto, não se caracteriza o compromisso profissional, a responsabilidade que as enfermeiras deveriam assumir neste momento. Não se percebe a essência do papel do(a) enfermeiro(a) prôpriamente dito; nenhuma ação que seja exclusivamente dele(a).

Quanto à percepção das enfermeiras sobre a admissão, vê-se que seus pontos de vista são diferentes e que apesar de verbalizarem a importância do procedimento em diferentes aspectos, encontram-se distanciadas da criança e da família; na unidade, não se verifica uma atuação comum e congruente aos princípios e valores mencionados por elas. Não estão fazendo aquilo no qual dizem acreditar. Será que, pelo menos, estão conscientes de toda esta contradição existente entre o seu pensar e o seu agir? E mesmo a assistência física. . . será que está sendo prestada adequadamente?

Estas e muitas outras indagaçðes podem ser feitas. Não com a intenção de se obter uma resposta absoluta para cada uma delas, mas no sentido de que, à medida que se levantam dúvidas e incertezas, abre-se o caminho para a reflexão e novos horizontes podem ser conquistados. Em relação à problemática analisada, acreditamos que novas soluções alternativas podem ser apontadas.

MADEIRA, L. M. Nursing behavior during the admission of a child to the hospital. Rev. Esc. Enf. USP, São Paulo, 18(3): 235-253, 1984.

A qualitative analysis is made of the nursing procedure of admitting a child to a governmental general hospital, with emphasis upon to the role of the nurse. The purpose of the analysis is to obtain data which could facilitate the understanding of the nurse's involvement in this procedure. The data will later be used in a participative research project which will be made with the nursing team in a pediatric ward.

\section{REFERÊNCIAS BIBLIOGRÁFICAS}

1. ALEXANDER, M. M. \& BROWN, M. S. Diagnóstico na enfermagem pediátrica. Sáo Paulo, Andrei, 1978. 289 p.

2. BARBOSA, L. T. Aspectos psico-sociais da assistência à criança. Sêo Paulo, Nestlé - Serviço de Informação Científica, /s.d./ (Temas de Pediatria, 9).

3. BOSI, E. Cultura de massa e cultura popular: leituras de operárias. Petrópolis, Vozes, 1981.192 p.

4. BOWLBY, J. Cuidados maternos e saúde mental. São Paulo, Martins Fontes, 1981. 255 p.

5. CONCEIÇÃO, J. A. N. et alii. Modelo para atendimento global à criança em um hospital-escola. Rev. Saúde Pública, São Paulo, 8(4): 341-7, dez. 1974.

6. FERREIRA-SANTOS, C. A. A enfermagem como profissão: estudo num hospital-escola. Sáo Paulo, Pioneira, 1973.176 p. 
7. HERTL, M. Manual de puericultura y pediatría para enfermeras. Barcelona, Toray, 1976. 548 p.

8. MACHADO, D. M. \& MACHADO, E. M. Cuidados psicológicos à criança hospitalizada. Rev. Hosp. Clin., São Paulo, 11(4):205-8, jul./ago. 1956.

9. MADEIRA, L. M. et alii. Problemas de internação em pediatria Rev. Gaúcha Hosp., Porto Alegre, 8(3):112-8, set. 1980.

10. MARCONDES, E. Pediatria, doutrina e ação. São Paulo, Sarvier, 1973.398 p.

11. MENZIES, I. E. P. El funcionamento de los sistemas sociales como defensa contra la ansiedad. In: \& JAQUES, E. Los sistemas sociales como defensa contra la ansiedad. 2. ed. Buenos Aires, Hormé, 1974. 122 p.

12. MINZONI, M. A. A função integrativa própria do profissional de enfermagem. Enf. Atual, Rio de Janeiro, 4(14):10-2, set./out. 1981.

13. NOWINSKI, M. A. \& RIPA, J. C. La investigación en los hospitales. Educ. Med. Salud, Washington, 14(4):355-70, Nov. 1980.

14. PETRILlO, R. N. M. \& SANGER, M. D. S. Cuidado emocional del niño hospitalizado. México, La prensa médica mexicana, 1975. $318 \mathrm{p}$.

15. RIBEIRO, M. N. F. Contatos da criança hospitalizada com a equipe de enfermagem em um hospital de ensino governamental. São Paulo, 1981. 77 p. (Dissertação de Mestrado - Escola de Enfermagem da USP).

16. ROBERTSON, J. Some responses of young children to the loss of maternal care. Nurs. Times, London, 49(16):382-6, Apr. 18, 1953.

17. ROCHA, D. N. A enfermagem e a criança. Rev. Bras. Enf., Brasıllia, 32(3):245-50, jul./set. 1979.

18. ROSKIES, E. et alii. Emergency hospitalization of young children: some neglegeted psychological considerations. Med. Care, Philadelphia, 13(7):570-81, Jul. 1975.

19. SPITZ, R. A. O primeiro ano de vida: um estudo psicanalítico do desenvolvimento normal e anormal das relações objetais. São Paulo, Martins Fortes, 1979. 349 p. 


\section{ANEXO 1}

\section{PRIMEIRA OBSERVAÇÃO}

Comunicada a internação à enfermeira $\mathrm{A}$ às 16 horas. Criança chega às $17 \mathrm{~h} 20 \mathrm{~min}$, acompanhada dos pais e de um funcionário do PMI.

Criança de 8 anos de idade; sexo feminino; suspeita diagnóstica de Tumor Osseo; não consegue deambular sem apoio; sendo admitida para clfnica ortopédica.

Enfermeira A fala aos pais, no balcão de entrada, que terão que aguardar o médico porque ele não é da pediatria. Ela irá chamá-lo.

Enquanto os pais aguardam, entra o grupo médico da ortopedia para a visita habitual às pacientes e o residente diz aos pais que deverão aguardá-lo.

Enfermeira A leva a mãe para dar banho na criança, oferece-lhe roupa da pediatria e explica-lhe como funciona o chuveiro. Mãe cuida da filha com delicadeza; conta-me que vieram de longe, da Bahia, e que precisava tomar "banho de assento", uma vez que viajou o dia inteiro (mais de 24 horas).

Enfermeira A conversa com o pai, tentando descobrir para onde irão após internarem a criança. Encaminha a mãe a outro chuveiro para tomar banho.

A criança é levada para a enfermaria e assentada na cama. Enfermaria com mais 3 crianças lactentes. Criança com fácies triste, respondendo baixinho ao que lhe é perguntado pela auxiliar.

Auxiliar de enfermagem $a$ coloca-lhe o termômetro; pergunta-lhe delicadamente, qual a "perninha" que dói; faz anotaçð̃es no prontuário. Diz à criança que quando precisar fazer "cocô" ou "xixi" deve pedir-lhe que a ajude a ir ao banheiro.

Criança permanece assentada na cama e não aceita o convite da auxiliar $a$ para se deitar. Vê a televisão pelo visor, na outra enfermaria e mostra interesse em ir ver.

A auxiliar percebe seu interesse, pergunta-lhe se quer ir lá, oferece-lhe os chinelos e ajuda-a a caminhar até a outra enfermaria, deixando-a lá assentada.

Mãe entra na enfermaria e diz à auxiliar $a$, mostrando-se bastante contente, que a "enfermeira" lhe disse que poderá visitar a filha todos os dias. 
Enfermeira A comenta comigo que está preocupada com os pais; arranjou-lhes jantar e agora não sabe como farão para dormir pois a assistente social neste horário não está mais para providenciar abrigo para os mesmos. Disse ter providenciado a admissão da criança, sem o exame médico, porque sabe que o residente vai demorar e os pais já esperaram muito.

Enfermeira A faz toda a parte burocrática da admissão: abertura do prontuário, registro no livro; porém, não elabora o plano de cuidados de enfermagem. 


\section{ANEXO 2 \\ PLANO DE CUIDADOS}

Plano de cuidados elaborado pela enfermeira do plantão noturno, após prescrição médica:

Diagnóstico: Tu ósseo

Prescrição: Dieta

Sinais vitais

Não forçar a perna para deambular

Anotar eliminações 


\section{ANEXO 3}

\section{SEGUNDA OBSERVAÇÃO}

Pedida vaga à enfermeira B às $13 \mathrm{~h} 30 \mathrm{~min}$, para uma criança infectada por Pseudomonas e que precisava de isolamento. Ás $14 \mathrm{~h} 30$ min chega a criança, acompanhada da tia e de um auxiliar de enfermagem do PMI.

Criança de 4 anos; sexo feminino; proveniente de outro hospital; em pós-operatório de obstrução intestinal; infectada; colostomizada; estado geral precário. Veio para se submeter à nutrição parenteral. Chega em cadeira de rodas, em soroterapia. Com fáceis triste; desconfiada; olhar alerta e atento.

$E$ recebida pela médica residente e pela enfermeira $B$, que não falam com a criança nem com a acompanhante. E levada em silêncio, através do corredor, até a enfermaria. Há dificuldade para se colocar a criança no berço por suas próprias condições (sutura de uns $15 \mathrm{~cm}$ no abdomen, com sinais de infecção, drenando; com bolsa de colostomia; reagindo à manipulação por causa da dor) e também porque, no momento, está faltando roupa de cama na unidade.

Enfermeira B bombeia o equipo de soro (obstruído por refluxo de sangue) e pergunta à criança se dói.

Criança olha apavorada tudo que é feito ao seu redor.

Residente chega e pergunta à enfermeira se vai precisar da acompanhante e esta responde que ela só precisa passar no serviço social.

Sai a acompanhante e a criança chora copiosamente chamando por ela.

Enfermeira B diz: "Ela não poderá ficar com você não, filha", de forma bastante impessoal.

Criança continua chorando com olhar apavorado.

Enfermeira B providencia vidro para controle de diurese, entra e sai da enfermaria, criança continua chorando e ela nada diz. Traz água e leite, mas a criança não aceita.

Residente examina a criança; volta a acompanhante.

Enfermeira, no corredor, se dirige a ela e diz-lhe que "se quiser pode ficar com a criança porque ela ficará no isolamento e aí é permitido. Se puder vai ser muito bom". Não dá outras explicações. 
Entra a auxiliar de enfermagem $b$; abre o prontuário, verifica sinais vitais; pergunta como a criança se chama, sem se dirigir a alguém, especificamente; preenche o cabeçalho do prontuário.

19 horas - Criança no leito já arrumado, feito curativo abdominal, já com prescrição médica. 
ANEXO 4

\section{PLANO DE CUIDADOS}

Plano de cuidados elaborado pela enfermeira B:

Sinais vitais

Dieta

Trocar bolsa de colostomia 